\title{
MUTAGENESIS OF HUMAN CELLS IN VIVO AND IN VITRO.
}

The goal of our research is to develop means to observe point mutational spectra in human cell cultures and human cell samples and to use the technology to discover the causes of point mutations in humans.

We have combined Fischer and Lerman's denauring gradient gel electrophoresis, high fidelity DNA amplification, and quantitative mutational measurements in a $104 \mathrm{bp}$ sequence within the third exon of the hprt gene in cultured human TK6 cells in order to observe predominant point mutations. We have now characterized the mutations arising spontaneously or after treatment with ICR-191, MNNG, benzo( $\alpha$ )pyrene diol epoxide, ultraviolet light, hyperbaric oxygen, and hydrogen peroxide.

The method is sensitive enough to observe an individual mutant fraction as low as $10^{-8}$.

We have extended the technology to include the use of PCR mediated addition of temperature stable clamp sequences so that, under conditions in which a sequence is part of a selectable genetic marker, point mutations may all be observed regardless of relative thermal stability in the native sequence. The utility of this step has been demonstrated by determining the point mutational spectrum for spontaneous and six mutagen-induced conditions in the first 80 bp of exon 3 of hprt.

However, most cells of human tissue samples cannot be grown in culture to select mutants. Furthermore, the hprt $(-)$ mutant fractions found in human peripheral $\mathrm{T}$ cells by Morley, Albertini, and later ourselves are lower than $10^{-5}$. Our studies to date also indicate that one needs 1000 separate mutations to characterize the mutational spectrum of a $100 \mathrm{bp}$ sequence with adequate $( \pm 20 \%)$ statistical precision. These limits pointed us toward development of a means to study isolate mutants sequences without regard to phenotype and to use sequences within multicopy genes. Independence from phenotypic selection eliminates the need to grow cells from tissues; multicopy genes reduce the tissue sample size required.

To this end, we have developed the technology necessary to separate mutant from nonmutant DNA sequences prior to use of high fidelity DNA amplification. Working with backround and benzo $(\alpha)$ pyrene diol epoxide induced mutations in exon $3 \mathrm{hpr}$ we are now able to observe individual mutant fractions low as $10^{-8}$. This sensitivity is more than sufficient to characterize 
point mutations in a gene such as hprt in which human $T$ cell null mutants occur at a frequency of $10^{-6}$ to $10^{-5}$ in vivo.

One last technical step: finding a means to study mutations in any DNA sequence in human tissues has recently been underiaken. A reagent DNA containing a themal stable clamp is purified by denaturing gradient gels and used as a template for primer extension from sample restriction fragments to place the sample's mutant sequences in a context suitable for mutational spectrometry. Reconstruction studies to measure the sensitivity of this approach using the ras genes are now in progress.

Our studies of the hprt(-) spectra of ICR-191, MNNG, and ultraviolet light have been accepted for publication. Manuscripts describing benzo( $\alpha)$ pyrene diolepoxide, oxygen, and hydrogen peroxide, as well as spontaneous mutation, are being readied for submission this summer.

This year effort already underway and consists of studies of a series of in vitro human cell genotypic spectra for benzo( $\alpha$ )pyrene diolepoxide, MNNG, and spontaneously induced mutation.

Most important, however, is the study in progress of background and spontaneous mutation in the $\mathrm{T}$ cells of 5 human donors. Using a multicopy mitochondrial sequence, the genotypic spectra of freshly ijolated $T$ cells is being cornparied to the mutants arising spontaneously when the donors' $T$ cells are grown in vitro. We expect to see, for the first time, the distribution and kinds of point mutants arising in humans. We hope to discover whether or not the mutations arising in human $T$ cells may be ascribed to non-spontaneous causes.

\section{RESEARCH REPORT}

1. MUTATIONAL SPECTRA IN HUMAN CELLS: 6TG SELECTED PHENOTYPE EXON 3 HPRT

\section{A. Introduction}

In a series of experiments using cultured TK6 cells and their MNNG-resistant derivative, MT-1, we have characterized the predominant point mutations arising in independently treated cultures. Each mutagen was studied in essentially the same way. Cultures were large enough so that at least surviving individual mutants arising at initial fractions of $10^{-7}$ would be present among $10^{9}$ surviving cells. 
Cultures were grown with daily dilution for 6 days to permit expression of the $6 \mathrm{TG}^{\mathrm{R}}$ phenotype. 6TG was then added to the culture and some 10-14 days elapsed before exponential growth of the $6 \mathrm{TG}^{\mathrm{R}}$ cells was detected by particle counting. DNA was isolated from the $6 \mathrm{TG}^{\mathrm{R}}$ population, high fidility amplification, with or without an added thermostable sequence, was carried out and the products were boiled and reannealed en masse to create heteroduplexes between mutant and wild type hprt exon 3 sequences.

The high fidelity amplification procedure was crucial to the sucess of this approach, and has been fully described in Keohavong P. and Thilly W.G. (1989) Fidelity of DNA polymerase in DNA amplification. PNAS, 86:9253-7 and Keohavong P. and Thilly W.G. (1989) Fidelity of DNA amplificatior in vitro. (1989) In: Ehrlich H.A. et al, eds. Polymerase Chain Reaction, Cold Spring Harbor Laboratory Press, New York pp. 19-24.

\section{B. $M N N G$ and ICR-191}

These two chemicals were proposed as examples of a base pair substitution mutagen (MNNG) and frame shift mutagen (ICR-191) according to the early findings of Benzer and Freese using bacteriophage. Our original observations show that MNNG induces solely GC $\rightarrow$ AT transitions and ICR-1 1 1 solely +1 bp deletions within hprt exon 3 and these have been described in a pa. $a_{1}$ er in press: Cariello N.F., Keohavong P., Kat A.G. and Thilly W.G.(1990) Molecular analysis of complex human cell populations: Mutational spectra of MNNG and ICR-191. Mutation Research. These data are summarized in Table 1 and 2. Further progress not yet in manuscript form has been provided in the form of studies of the MNNG-resistant subclone of our TK6 line. MT-1 (vis. Table 3) Ms. Alexandra Kat has found a series of MNNG-induced hotspots in hprt exons 2 ard 3 for this line. All are GC $\rightarrow$ AT transitions as in the parent line, but there is a clear difference between the MNNG induced spectra in the first $80 \mathrm{bp}$ of exon 3 .

TABLE 1

ICR-191 MUTATIONAL SPECTRUM TK-6 CELLS EXON 3 HPRT

Position

$276-278$

(CCC)

292-297

\section{Eind}

$$
+\mathrm{C}
$$

$+\mathrm{G}$
\% $6 \mathrm{Tg}^{\mathrm{R}}$

14

23
Frequency

$2.2 \times 10^{-5}$

$3.7 \times 10^{-5}$

(GGGGGG) 
TABLE 2

MNNG MUTATION SPECTRUM

TK-6 CELLS EXON 3 HPRT

\begin{tabular}{|c|c|c|c|}
\hline Pesition & Kind & $\% 6 \mathrm{TG}^{\mathrm{R}}$ & Frequency \\
\hline 293 & $\mathrm{GC} \rightarrow \mathrm{AT}$ & $-15 \%$ & $\sim 7 \times 10^{-6}$ \\
\hline 294 & $\mathrm{GC} \rightarrow \mathrm{AT}$ & $\sim 12 \%$ & $\sim 5 \times 10^{-7}$ \\
\hline
\end{tabular}

TABLE 3

MNNG MUTATTONAL SPECTRUM MT-1 CELLS

EXON 3 HPRT

$\begin{array}{rccc}\text { Position } & \text { Kind } & \text { \%6TG }^{\mathrm{R}} & \text { Erequency } \\ 294 & \mathrm{GC} \rightarrow \mathrm{AT} & 10 \% & 2 \times 10^{-3} \\ 297 & \mathrm{GC} \rightarrow \mathrm{AT} & 10 \% & 2 \times 10^{-3} \\ 322 & \mathrm{GC} \rightarrow \mathrm{AT} & 1 \% & 2 \times 10^{-4}\end{array}$

\section{EXON 2 HPRT}

\begin{tabular}{rccc} 
Position & Kind & \%6 $6 \mathrm{TG}^{\mathrm{R}}$ & $\underline{\text { Frequency }}$ \\
\hline 132 & $\mathrm{GC} \rightarrow \mathrm{AT}$ & $2.5 \%$ & $5 \times 10^{-4}$ \\
140 & $\mathrm{CG} \rightarrow \mathrm{TA}$ & $1 \%$ & $2 \times 10^{-4}$ \\
159 & $\mathrm{CG} \rightarrow \mathrm{TA}$ & $1 \%$ & $2 \times 10^{-4}$
\end{tabular}

\section{Ulmaviolet Light}

Hotspots induced by ultraviolet light are described in a manuscript accepted for publication pending revision: Keohavong P., Liu V.F. and Thilly W.G.(1990 est.) Analysis of point mutations induced by ultraviolet light in exon 3 of the human HPRT gene. Molecular and Cellular Biology. We found our observations to be generally in accord with prior studies of phage, bacteria, and rodent cells insofar as we found a variety of base pair substitutions, small deletions, and several tandem mutations (vis Table 4). 
TABLE 4

UY MUTATIONAL SPECTRUM

(from Keohavong)

$\begin{array}{rccc}\text { Position } & \text { Kind } & \text { \%0 } 6 \mathrm{TG}^{\mathrm{R}} & \underline{\text { Erequency }} \\ 293 & \mathrm{GC} \rightarrow \mathrm{AT} & 2.7 \% & 6.5 \times 10^{-7} \\ 294 & \mathrm{GC} \rightarrow \mathrm{AT} & 0.8 \% & 2 \times 10^{-7} \\ 369 & \mathrm{AT} \rightarrow \mathrm{CG} & 1.6 \% & 4 \times 10^{-7} \\ 381 & \mathrm{AT} \rightarrow \mathrm{CG} & 0.8 \% & 2 \times 10^{-7} \\ 381 & \mathrm{AT} \rightarrow \mathrm{GC} & 1.3 \% & 3 \times 10^{-7}\end{array}$

D. Spontaneous. oxygen. and hydrogen peroxide induced mutation

These experiments were performed at very low mutant fractions in order to discover if spontaneous mutation in human cells could be accounted for by damage via active oxygen species. In summary, the spontaneous spectrum in exon $3 \mathrm{hpr}$ was significantly different than from oxygen induced and $\mathrm{H}_{2} \mathrm{O}_{2}$ spectra which, in turn, were different from each other. Spontaneous mutation involved a single and double base pair deletion; oxygen, while inducing many $6 \mathrm{TGR}^{\mathrm{R}}$ muttants yielded, $\mathrm{n} \Omega$ hotspots (vacant spectrum) in exon 3; and $\mathrm{H}_{2} \mathrm{O}_{2}$ induced a series of transversion mutations. There data are summarized in Table 5.

TABLE 5

SPONTANEOUS, OXYGEN- AND $\mathrm{H}_{2} \mathrm{O}_{2}$ - INDUCED SPECTRA TK6 CELLS EXON 3 HPRT

\begin{tabular}{rccc}
$\begin{array}{r}\text { Position } \\
\text { Spontaneous }\end{array}$ & Kind & ${\text { \% } 6 \mathrm{TG}^{\mathrm{R}}}$ & Erequency \\
\hline $\begin{array}{r}\text { bp } 322-323 \\
(\mathrm{TGGA})\end{array}$ & $($ - GG) & 1.0 & $4 \times 10^{-8}$ \\
bp 341 or 342 & $(-\mathrm{A})$ & 1.2 & $4.8 \times 10^{-8}$ \\
$(\mathrm{GAAT})$ & & &
\end{tabular}

Oxygen

$\mathrm{H}_{2} \mathrm{O}_{2}$

exon $3 \quad \leq 0.1 \quad \leq 4 \times 10^{-9}$

$287 \quad$ GC $\rightarrow$ CG

$328 \quad \mathrm{GC} \rightarrow \mathrm{CG}$

$0.4 \quad 1.6 \times 10^{-8}$

$0.7 \quad 2.8 \times 10^{-8}$ 
344

359-363

(ATCCATTC)

\section{E. Benzo( $\alpha)$ pyrene diol epoxide}

This metabolite of the ubiquitous air pollutant is being used as our standard because very high $6 \mathrm{TG}^{\mathrm{R}}$ mutant fractions arise under relatively low killing conditions as well as for its intrinsic potential importance in environmental mutagenesis. A manuscript is in preparation.

TABLE 6

Benzo( $\alpha$ )pyrene diol epoxide mutation spectrum

TK6 cells exon 3 hprt

\begin{tabular}{rccc} 
Position & Kind & $\frac{\text { \%6 } 6 \mathrm{TG}^{\mathrm{R}}}{1.5 \%}$ & $\underline{\text { Erequency }}$ \\
\hline 250 & $\mathrm{GC} \rightarrow \mathrm{TA}$ & $2.5 \%$ & $2.25 \times 10^{-6}$ \\
256 & $\mathrm{GC} \rightarrow \mathrm{TA}$ & $1 \%$ & $3.75 \times 10^{-6}$ \\
275 & $\mathrm{GC} \rightarrow \mathrm{TA}$ & $1 \%$ & $1.5 \times 10^{-6}$ \\
282 & $\mathrm{GC} \rightarrow \mathrm{TA}$ & $1 \%$ & $1.5 \times 10^{-6}$ \\
293 & $\mathrm{GC} \rightarrow \mathrm{TA}$ & $1 \%$ & $1.5 \times 10^{-6}$ \\
293 & $\mathrm{GC} \rightarrow \mathrm{AT}$ & $1.6 \%$ & $1.5 \times 10^{-6}$ \\
294 & $\mathrm{GC} \rightarrow \mathrm{TA}$ & $1.5 \%$ & $2.4 \times 10^{-6}$ \\
296 & $\mathrm{GC} \rightarrow \mathrm{CG}$ & $1.6 \%$ & $2.25 \times 10^{-6}$ \\
297 & $\mathrm{GC} \rightarrow \mathrm{TA}$ & $1.5 \%$ & $2.4 \times 10^{-6}$ \\
$292-297$ & $\mathrm{GC} \rightarrow$ deletion & $1 \%$ & $2.25 \times 10^{-6}$ \\
392 & $\mathrm{AT} \rightarrow \mathrm{TA}$ & $1.5 \%$ & $1.5 \times 10^{-6}$ \\
$392 / 393$ & $\mathrm{AT} \rightarrow$ deletion & & $2.25 \times 10^{-6}$
\end{tabular}

\section{PHENOTYPE - INDEPENDENT MU'TATIONAL SPECTRA IN HUMAN CELLS}

\section{A. Incroduction,}

Since early husbandmen recognized genotypic variants on the basis of coat color, geneticists have depended on the phenotype of crosses, recombinants, and mutants to detect the occurence of genetic change. By separating mutant DNA from wild type DNA sequences on the basis of their cooperistive equilibrium melting temperature, Fischer and Lerman, gave us the tool necessary to remove the screen of phenotype. We first use a denaturing gradient to separate the mass of wild type DNA as homoduplexes from all point mutant DNA bound in heteroduplexes 
with wild type DNA. Next, we recover the hete oduplexes by electroelution and amplify them with our hi-fi PCR protocol. We convert the mutants to heteroduplexes again with excess wild type DNA and separate them again on a denaturing gradient gel. An autoradiogram reveals the band patterns and serves as a template to excise individual bands which lead to DNA sequences for every prominent mutant within a point mutational spectrum.

There are two variants in this procedure.

In the first, the sequence of interest is a low melting domain contiguous to a high melting domain which acts as a natural clamp. In these cases -- hprt exon 3 , exons 5,6 , and 8 , sequences in the multicopy genes for $18 \mathrm{~S} \mathrm{rRNA}$, or mitochondria -- one simply prepares a restriction digest fraction containing the desired fragment, boils, reanneals, and proceeds to the first denaturing gradient gel.

In the second variation, the desired sequence is not flanked by a natural clamp and one nnust be added. Examples of such sequences are exons 1 and 2 of the c-ras oncogene family. However, PCR mediated clamp addition is not suitable at this step because even the most faithful DNA polymerase -- T4 -- will create more new mutants in copying the wild type sequences in a single cycle (!) than are generally present in a cell sample. The error rate $(f)$ for $T 4$ is between $10^{-6}$ and $10^{-7}$ mutations per base pair per doubling. A single round, copying 200 bp from $10^{9}$ sample copies, yields at least $2 \times 10^{4}$ mutant strands compared to $10^{4}$ mutants in a human tissue sample of the same size.

Fortunately, one of the Ph.D. candidates on this project, Ms. Rita Cha, has devised a means to overcome this problem. First, she adds the high melting clamp to the desired sequence by PCR. (Other means such as mass production on a bacterial vector would aiso serve.) Second, she boils and reaneals the fragments, forcing the PCR created mutants into the heteroduplex form with wild type. Third, she isolates the wild type homoduplexes from contaminating mutants on a denaturing gradient gel. This homoduplex material is electroeluted and constitutes a reagent DNA containing the desired DNA sequence free of mutants and linked to high melting clamp.

This reagent is now added in excess (10x) to the sample restriction digest, boiled and reannealed. Half of the sample sequences will now be in a configuration in which the $3^{\prime}$ end of the sample fragment can be used as a primer to copy the 5 end of the reagent clamp sequence. The result is that both wild type and mutant sample sequences are now in duplexes with the mutant-free reagent with a high melting clamp. Neither sample wild type nor mutant sequences have been 
copied by DNA polymerase and, therefore, no polymerase induced errors have beed introduced. The subsequent steps are identical to handling DNA sequences containing natural high melting clamps. The protocol is diagrammed in Figure 1.

\section{B. Genotypic Spectra from Mutagen Treated Human Cell Cultures}

Anticipating the development of the phenotype independent procedure, we have carefully frozen and stored all TK6 and MT-1 treated cultures at $138 \mathrm{~K}$ in sufficient numbers to examine the resulting "genotypic spectra" without the time and expense of repeating the mutational assays. In addition to the spontaneous mutations and the mutagens summarized above for which $6 \mathrm{TG}^{\mathrm{R}}$ spectra have been obtained in exon 3 , hprt, we have in our freezer human cell cultures treated with a wide variety of environmetal mutagens for which we have previously obtained quantitative mutant fraction data relative to the hprt and tk (thymidine kinase) genes.

\section{TABLE 7}

List of mutagens for which treated human cell samples are available and suitable for genotypic mutational spectrometry

\section{Sponianeous mutation}

Alkvlating Agents

$\mathrm{MNU}$

ethylene oxide

MNNG

styrene oxide

EMS

\section{Ultraviolet Light $(254 \mathrm{~mm})$}

\section{Q2 Cascade}

$\mathrm{x}$-rays

oxygen $(.8 \mathrm{mM})$

$\mathrm{H}_{2} \mathrm{O}_{2}$

potassium superoxide

\section{$\underline{\mathrm{PAH}}$}

benzo $(\alpha)$ pyrene

benzo $(\alpha)$ pyrene diol epoxide (racemic)

benzo $(\varepsilon)$ pyrene

cyclopenta[c,d]pyrene 
fluoranthene

1,6 dinitropyrene

acenaphthylene

Pyrolysis Products

2,6 dimethyloxyphenol

4 - propenylanisole

4 - allylanisole (estragole)

lignite pyrolysate

Urban $A$ ir Samples

Washington, D.C.

St. Louis, MO

Food-Borne Toxins

$\begin{array}{ll}\text { aflatoxin B1 } & \begin{array}{l}\text { metanil yellow } \\ \text { quercetin }\end{array} \\ \text { orange II }\end{array}$

Qther

4 aminobiphenyl

nitric oxide

cis-platinum

Of these two -- benzo( $\alpha$ )pyrene diol epoxide and MNNG -- are in the process of analysis for genotypic spectra in hprt exon 3 (bpde) and in all hprt exon containing sequences that contain natural flanking clamps (MNNG).

Figure 2 shows a direct comparison between the set of mutants obtained by 6TG (phenotypic) selection and by genotypic selection with DG gels. Shown are seven lanes on a denaturing gradient gel in which hprt exon 3 DNA of three cultures has been processed.

In the first three lanes from the left, $6 \mathrm{TG}^{\mathrm{R}}$ cells were first selected by growth in spinner culture en masse. In the next three lanes, the DNA was processed without $6 \mathrm{TG}$ selection by the genotypic selection method outlined above, ie. DGGE $\rightarrow$ hifi PCR $\rightarrow$ DGGE.

The first and second lanes show a series of mutant bands which have presumably arisen over the course of time in maintaining TK6 stocks with intermittant treatments to reduce the $6 \mathrm{TG}^{\mathrm{R}}$ 
mutant fraction. Some mutant bands are shared by the sistor cultures, some are not. The intense mutant bands represent about $2 \%$ of the $6 \mathrm{TG}^{\mathrm{R}}$ DNA sequences. The $6 \mathrm{TG}^{\mathrm{R}}$ fraction in these cultures was $2 \times 20^{-6}$, so the intense bands represent initial mutant fractions of about $4 \times 10^{-8}$.

When the DNA of these untreated stock cultures is processed without benefit of 6TG selection, as in the $4^{\text {th }}$ and $5^{\text {th }}$ lanes, then, in addition to the bands observed in lanes 1 and 2 , a whole series of new bands appear. These presumably represent DNA sequence changes which did not confer $6 \mathrm{TG}$ resistance, ie. cryptic mutations. (In related studies of MNNG induced mutants in which sequences have been obtained for some bands, an example of a wobble changing from one leucine codon to another, has been found.) We have integrated the counts found in these two stock cultures mutant heteroduplex regions and find that the ratio of unselected/selected mutant fraction is approximately seven. However, these are stock cultures, not cultures in which care has been taken to observe only spontaneous hotspots as was taken for the data of Table 5. We use this number as a rough means to gauge our expectation of total unselected mutant number per $100 \mathrm{bp}$ when we have knowledge of the $6 \mathrm{TG}^{\mathrm{R}}$ mutant fraction.

The results with the bpde treated culture show two $6 \mathrm{TG}^{\mathrm{R}}$ mutants ai low frequency as reported in Table 6 . However, when the phenotype independent or genotypic spectrum is observed (lane 6, Figure 2), it is clear that bpde has induced an additional set of point mutations which do not produce the $6 \mathrm{TG}^{\mathrm{R}}$ phenotype. This experiment with bpde has now been repeated in quadruplicate, and the sequencing of each cryptic point mutant is in progress. The process developed appears to be applicable to any DNA sequence neighbored by a relatively thermally stable "clamp" with a detection limit of 100 mutant molecules or a frequency of $10^{-8}$, whichever is larger in terms of mutant molecules.

\section{Genotypic Spectra from Peripheral Blood T-Cell Samples}

In order ot discover to what extent humans suffer environmetal mutagen induced point mutations, we have spent the last two years developing the means to perform what is, conceptually, a very simple experiment.

We reason that the mutations in blood T-cells have risen by spontaneous mutation or induced mutation. We already know that spontaneous mutation in cultured T-cells exon 3 of hprt is characterized by two small deletions (Table 2). To find out what spontaneous mutation looks like in T-cells, John Hanekamp first devised a means to exponetially expand a T-cell sample from human donors. To do this he used periodic addition and withdrawal of the necessary growth factor, IL-2, from cutures of phytohemaglutin in stimulated T-cells drawn from male and female 
donors 25 - 35 years old. Using fluorescent antibodies to identify the various subsets of T-cells, he found this method maintained a constant ratio of $\mathrm{T}$-cell types during 15 - 20 generations of growth in vitro.

From each of 5 donors, he has taken multiple $10 \mathrm{ml}$ blood samples (10 7 T-cells each) and from these samples prepared multiple cultures, each starting with 100 T-cells for population expansion. 100 cells would not be expected to contain any mutants by chance so mutants found in all replicate small cultures after expansion would represent spontaneous mutational hotspots.

The first DNA sequence to be studied contains a 220 bp low melting domain of the mitochondrial genome. Each cell contains about $10^{4}$ mitochondrial DNA copies. Expansion of 100 cells ( $10^{6}$ copies) for 15 generations $(32,000 \mathrm{x})$ yields $32 \times 10^{9}$ copies which should be more than sufficient for analysis of the spontaneous genotypic mutational spectra.

In a separate series of steps, the actual T-cell sample will be analyzed. The spectra from the direct $T$-cell sample should reflect the sum of spontaneous and induced mutations in the donor.

Comparison of the sample spectra to the spontaeous spectra from cells of the same donor should permit us to find out if human T-cells do, in fact, suffer mutation by nonspontaneous (induced) pathways. The use of five separate donors should allow us to observe any similarity among spontaneous or induced spectra that may exist.

\section{PROPOSAL 1 NOVEMBER 1990 TO 31 OCTOBER 1991}

1. Obtain the mutational spectra of human T-cells in vivo and compare to donor matched controls in vitro spontaneous spectra.

Five human donors will be chraterized for mutations in a 220 bp sequence of the mitochondria. (Mr. John Hanekamp)

2. Obtain the mutational spectra of human T-cells in patients treated with cis-platinum as part of a chemotherapy regimin. Compare spectra before and as a function of time after treatment.

Patients, samples, and DNA isolation are performed at the Cytogenetics Unit of the Karolinska Hospital, Stockholm.

Obtain the mutational spectra of cis-platinum in human $\beta$ cell cutures in order to discover if our in-house $\because \mathrm{K}-6 \beta$ cell line is mutated in a manner similar to human $\mathrm{T}$-cells in vivo. (Dr. Ahmad Chaudhry)

3. Initiate studies of mutant DNA separation using temperature programmed capillary gel electrophoresis as a means to facilitate the analytical steps of mutational spectrometry. (Ms. Jia Chen) 
4. Attempt to discover if chromosomal level rearrangements occurring in human cells cluster as "hotspots" after treatment with clastogenic agents. This will be done by separating very large human genomic DNA fragments on a pulse field gel and then using PCR to find and enumerate fragments of increased size contaioning a marker sequence normally found in a small restriction fragment. (Dr. Ling Min Gao)

\section{DISCLAIMER}

This report was prepared as an account of work sponsored by an agency of the United States Government. Neither the United States Government nor any agency thereof, nor any of their employees, makes any warranty, express or implied, or assumes any legal liability or responsibinty for the accuracy, completeness, or usefulness of any information, apparatus, product, or process disclosed, or represents that its use would not infringe privately owned rights. Reference herein to any specific commercial product, process, or service by trade name, trademark, manufacturer, or otherwise does not necessarily constitute or imply its endorsement, recommendation, or favoring by the United States Government or any agency thereof. The views and opinions of authors expressed herein do not necessarily state or reflect those of the United States Government or any agency thereof. 
